\begin{tabular}{|c|c|c|}
\hline decartesian 9 & Jumal Matematika dan Aplikasi & \\
\hline & deOancterian & \\
\hline$=$ & $\begin{array}{c}\text { ISSN:2302-4224 } \\
\text { J o u r n a I h o m e p a g e: } \mathrm{https://ejournal.unsrat.ac.id/index.php/decartesian}\end{array}$ & deCartesian \\
\hline
\end{tabular}

\title{
Analisis Pengaruh Fasilitas dan Kualitas Layanan Terhadap Kepuasan Pelanggan (Studi Kasus: Klinik UKSW)
}

\author{
Ester Dwiningsih Putri Permatasari Santoso ${ }^{1}$, Bambang Susanto $^{1}$, Lilik Linawati ${ }^{*}$ \\ ${ }^{1}$ Program Studi Matematika-Fakultas Sains dan Matematika-UKSW, Jln. Diponegoro No. 52-60, Salatiga 50711, Indonesia \\ ${ }^{*}$ Corresponding author : lilik.linawati@staff.uksw.edu
}

\begin{abstract}
A B S T R A K
Penelitian ini bertujuan untuk mengetahui pengaruh fasilitas dan kualitas layanan yang terdiri dari layanan pendaftaran, layanan dokter, layanan obat dan laboratorium terhadap kepuasan pelanggan di Klinik Universitas Kristen Satya Wacana. Sampel diambil sebanyak 150 responden dari pelanggan Klinik Universitas Kristen Satya Wacana dengan metode quota sampling. Metode analisis yang digunakan adalah analisis regresi dan Fuzzy Quantification Theory I. Data yang diperoleh diolah dengan bantuan Microsoft Excel untuk analisis regresi dan aplikasi berbasis Matlab untuk Fuzzy Quantification Theory I. Hasil analisis menunjukkan bahwa kualitas layanan dokter umum memberikan kontribusi terbesar terhadap kepuasan pelanggan.
\end{abstract}

\author{
INFO ARTIKEL \\ Diterima :9 April 2018 \\ Diterima setelah revisi : 8 Mei 2018 \\ Tersedia online $\quad:$ 30 Juli 2018 \\ Kata Kunci: \\ fasilitas, \\ fuzzy quantification theory I, \\ kepuasan pelanggan, \\ layanan, \\ regresi.
}

\section{PENDAHULUAN}

Masyarakat mulai menyadari bahwa kesehatan itu penting dengan memperhatikan hal-hal yang diperoleh dalam pelayanan kesehatan. Semua orang mengharapkan dapat memperoleh pelayanan kesehatan yang memadai dari penyedia jasa kesehatan. Hal ini menimbulkan persaingan diantara penyedia jasa yang ada untuk mempertahankan pelanggannya. Pelanggan yang merasa puas atas pelayanan yang diberikan oleh penyedia jasa kesehatan akan tetap mempercayai penyedia jasa tersebut untuk mengobatinya. Evaluasi secara berkala perlu dilakukan sebagai strategi dalam upaya meningkatkan layanan kesehatan. Evaluasi dilakukan dengan membagikan kuesioner kepada pelanggan dan biasanya data evaluasi direpresentasikan dalam bentuk kualitatif secara linguistik seperti baik, cukup, setuju, puas, dll. Padahal sebenarnya, untuk membandingkan evaluasi akan lebih mudah apabila ekspresi yang berbentuk kualitatif tersebut diubah dengan bentuk numeris sehingga dibutuhkan metode kuantifikasi untuk menganalisisnya. Analisis terhadap layanan dengan kepuasan pelanggan kebanyakan dilakukan untuk mengetahui adakah pengaruh antara layanan dengan kepuasan pelanggan. Untuk itulah pada penelitian ini dilakukan analisis untuk mengetahui pengaruh fasilitas dan layanan terhadap kepuasan pelanggan. Fasilitas dan layanan merupakan faktor yang berpengaruh kuat terhadap tingkat kepuasan pelanggan. Hal ini diperkuat oleh Mongkaren dalam hasil penelitiannya yang menyatakan bahwa fasilitas mempengaruhi kepuasan pelanggan [8]. Sementara itu, beberap artikel juga menyatakan bahwa layanan juga mempengaruhi kepuasan pelanggan ([1],[6]). Pada umumnya, metode kuantifikasi yang digunakan adalah regresi linier dimana secara umum persamaannya yaitu $y=a x+b$ [4]. Namun pada penelitian ini dilakukan menggunakan himpunan fuzzy.

Menurut [7], Fuzzy Quantification Theory I (FQT I) merupakan metode untuk mengendalikan data kualitatif dengan menggunakan teori himpunan fuzzy. FQT I juga disebut analisis regresi kualitatif . Tujuan FQT I adalah menentukan hubungan antara variabel kualitatif yang mempunyai rentang nilai o sampai $\mathbf{1}$, dan variabel-variabel numeris dalam fuzzy group. Karakteristik data yang dibutuhkan dalam FQT I seperti disajikan pada Tabel 1. 
Tabel 1. Karakteristik Fuzzy Quantification Theory I

\begin{tabular}{|c|c|c|c|}
\hline $\begin{array}{l}\text { No } \\
(k)\end{array}$ & $\begin{array}{c}\text { Eksternal Data } \\
(y)\end{array}$ & $\begin{array}{c}\text { Kategori } \\
\left(A_{1}{ }^{\infty \times} A_{i}{ }^{\infty \times 1} A_{p}\right)\end{array}$ & $\begin{array}{c}\text { Fuzzy Group } \\
\text { (B) }\end{array}$ \\
\hline 1 & $y_{1}$ & $\mu_{1}(1)^{m \infty} \mu_{i}(1)^{m \infty} \mu_{p}(1)$ & $\mu_{B}(1)$ \\
\hline 2 & $y_{2}$ & $\mu_{1}(2)^{m-1} \mu_{i}(2)^{m-\infty} \mu_{p}(2)$ & $\mu_{B}(2)$ \\
\hline 3 & $y_{3}$ & $\mu_{1}(3)^{\infty \times-} \mu_{i}(3)^{-\infty} \mu_{p}(3)$ & $\mu_{B}(3)$ \\
\hline$k$ & $y_{k}$ & $\mu_{1}(k)=\infty \mu_{i}(k)=\mu_{p}(k)$ & $\mu_{B}(k)$ \\
\hline$n$ & $y_{n}$ & $\mu_{1}(n)^{m \infty} \mu_{i}(n)^{m} \mu_{p}(n)$ & $\mu_{B}(n)$ \\
\hline
\end{tabular}

Tabel 1 menunjukkan karakterikstik Fuzzy Quantification Theory I dengan $n$ menyatakan banyaknya responden. Eksternal Data menunjukkan fungsi tujuan, $y_{k}$ adalah fungsi tujuan dari responden ke-k, Kategori $\left(A_{1} \times A_{i=1} A_{p}\right)$ dan Fuzzy Group (B) sebagai variabel independen.

Sama halnya dengan regresi secara umum, FQT I juga menentukan suatu fungsi linear dari beberapa kategori dengan $a_{i}$ sebagai parameter yang akan ditentukan, seperti disajikan pada persamaan (1)

$y_{k}=\sum_{i=1}^{p} a_{i} \mu_{i}(k)$

yang diharapkan variasi tujuan akan memberikan nilai error yang sangat kecil. Untuk itu, perlu disusun matriks sebagai berikut:

$$
\begin{aligned}
& y^{\prime}=\left[y_{11}, y_{2}{ }^{n{ }^{n}} y_{\mathrm{n}}\right] \\
& G=\left[\begin{array}{ccc}
\mu_{B}(1) & \ldots & 0 \\
0 & \cdots & \\
x_{\mathrm{w}} & \mu_{B}(n)
\end{array}\right] \\
& X=\left[\begin{array}{ccccc}
\mu_{1}(1) & \cdots & \mu_{i}(1) & \cdots & \mu_{p}(1) \\
\vdots & & \vdots & & \vdots \\
\mu_{1}(k) & \cdots & \mu_{i}(k) & \cdots & \mu_{p}(k) \\
\vdots & & \vdots & & \vdots \\
\mu_{1}(n) & \cdots & \mu_{i}(n) & \cdots & \mu_{p}(n)
\end{array}\right]
\end{aligned}
$$

Dengan demikian, error variance $\sigma_{R}^{2}$ untuk fuzzy group B adalah

$$
\sigma_{B}^{2}=\frac{1}{N(B)}(y-X a)^{y} G(y-X a)
$$

Karena $\frac{\partial \sigma_{\mathrm{R}}}{\partial a}=-2 X^{s} G y+2 X^{s} G X a$, maka

bobot kategori $a$ yang meminimumkan error variance diberikan oleh :

$$
a=\left(X^{t} G X\right)^{-1} X^{t} G y
$$

Persamaan (3) yang akan digunakan untuk menyusun persamaan regresi fuzzy pada persamaan (1). Dan Analisis FQT I kebanyakan sudah dilakukan di bidang pendidikan untuk mengetahui pengaruh komponen pembelajaran terhadap tingkat kelulusan mahasiswa ([2],[3],[5]). Dalam hal ini analisis FQT I akan digunakan untuk mendapatkan model pengaruh fasilitas dan kualitas layanan terhadap kepuasan pelanggan serta untuk mengetahui variabel yang memiliki pengaruh paling kuat terhadap kepuasan pelanggan di Klinik UKSW.

\section{METODE PENELITIAN}

Penelitian ini mengembangkan sistem untuk menganalisis pengaruh fasilitas dan kualitas layanan terhadap kepuasan pelanggan dalam bidang kesehatan di Klinik UKSW. Pengumpulan data menggunakan instrumen kuesioner untuk memperoleh data primer berupa penilaian pelanggan terhadap fasilitas, kualitas layanan dan kepuasan pelanggan dimana skor penilaian yang digunakan dengan skala 1 (sangat tidak setuju) sampai 4 (sangat setuju). Sampel diambil sebanyak 150 responden dengan metode quota sampling. Responden dalam penelitian ini adalah pelanggan di Klinik Univerrsitas Kristen Satya Wacana Salatiga. Data diambil pada bulan Oktober 2017.

\subsection{Teknis Analisis}

Analisa yang digunakan dalam penelitian ini adalah metode Fuzzy Quantification Theory I dengan variabel layanan pendaftaran, layanan dokter umum, layanan obat dan laboratorium sebagai fuzzy group. Selanjutnya, dilakukan tahapan sebagai berikut:

1. Normalisasi data yaitu membuat nilai variabel fasilitas dan fuzzy group (Layanan pendaftaran,layanan dokter, layanan obat dan laboratorium) pada selang [o, 1].

2. Penyusunan persamaan regresi dan fungsi keanggotaan fasilitas yaitu menyusun persamaan regresi untuk hubungan fasilitas dan kepuasan pelanggan dan membentuk fungsi keanggotaan fuzzy untuk fasilitas.

3. Pembentukan fuzzy Group yaitu menentukan variabel - variabel yang menjadi fuzzy group FQT.

4. Pengolahan data menggunakan Microsoft Excel untuk menyusun persamaan regresi hubungan fasilitas terhadap kepuasan pelanggan dan Matlab untuk menyusun persamaan regresi pada fuzzy group.

5. Penentuan model FQT yaitu menganalisa tiap fuzzy group untuk mendapatkan model berupa persamaan linier sehingga didapatkan bobot kategori dan penambahan kontribusi dari tiap fuzzy group.

6. Penarikan kesimpulan berdasarkan hasil analisa yang diperoleh.

\section{HASIL DAN PEMBAHASAN}

\subsection{Pengaruh Fasilitas Terhadap Kepuasan Pelanggan}

Variabel dalam penelitian ini adalah fasilitas, kualitas layanan dan tingkat kepuasan pelanggan dalam pelayanan kesehatan di Klinik Universitas Kristen Satya Wacana. Hanya ada satu kategori yang digunakan yaitu fasilitas. Tingkat ketersediaan fasilitas dapat direprentasikan sebagai himpunan fuzzy “Tinggi” dengan mengikuti pola grafik pada fungsi keanggotaan seperti pada Gambar 1. 


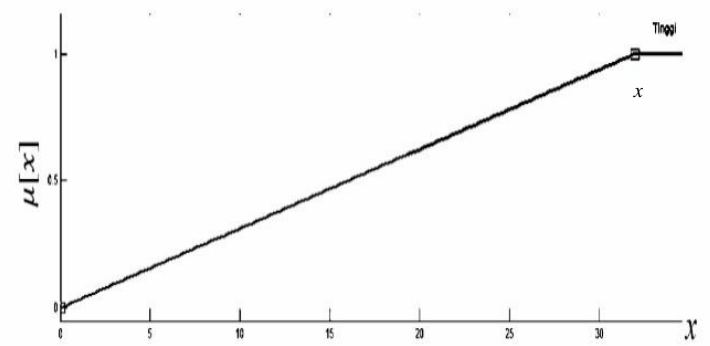

Gambar 1. Himpunan Fuzzy Tingkat Ketersediaan Fasilitas

dan fungsi keanggotaan fungsi untuk kategori fasilitas adalah

$$
\mu_{\text {tinggi }}[x]=\left\{\begin{aligned}
\frac{x}{32}, & 0 \leq x<32 \\
1, & x \geq 32
\end{aligned}\right.
$$

Dengan menggunakan regresi linier diperoleh hubungan fasilitas (x) dengan kepuasan pelanggan (y) sebagai berikut persamaan (5) dalam regresi biasa dan persamaan (6) dalam regresi fuzzy :

$$
\begin{aligned}
& y=5.7678+0.6541 x \\
& y=5.7678+20.9312 \mu[x]
\end{aligned}
$$

\subsection{Analisis Fuzzy Group}

Fuzzy group yang terbentuk pada penelitian ini adalah Fuzzy Group 1: Layanan pendaftaran, Fuzzy Group 2: Layanan dokter, Fuzzy Group 3: Layanan obat dan laboratorium.

Analisa fuzzy group dilakukan untuk mendapatkan persamaan fungsi linier diperoleh seperti pada Tabel 2:

Tabel 2. Model FQT

\begin{tabular}{ccc}
\hline & \multicolumn{2}{c}{ Persamaan } \\
\cline { 2 - 3 } Fuzzy Group & $\begin{array}{c}\text { Regresi } \\
\text { Biasa }\end{array}$ & $\begin{array}{c}\text { Regresi } \\
\text { Fuzzy }\end{array}$ \\
\hline \hline $\begin{array}{c}\text { Layanan } \\
\text { pendaftaran } \\
\text { Layanan } \\
\text { dokter } \\
\text { umum }\end{array}$ & $y=0.8945 x$ & $y=28.6255 \mu[x]$ \\
$\begin{array}{c}\text { Layanan } \\
\text { obat dan }\end{array}$ & $y=0.8950 x$ & $y=28.6404 \mu[x]$ \\
laboratorium & & $y=28.5873 \mu[x]$ \\
\hline
\end{tabular}

dari Tabel 2 dapat digunakan untuk menghitung kontribusi tambahan terhadap kepuasan pelanggan yang diberikan masing - masing fuzzy group. Dengan mempertimbangkan layanan pendaftaran, memberikan kontribusi tambahan terhadap kepuasan pelanggan sebesar 0.2404 (0.8945 - o.6541) atau 7.6943 (28.6255 - 20.9312). Perpotongan garis pada persamaan 6 dan persamaan layanan pendaftaran terjadi pada titik $(0.7496,21.4577)$ seperti Gambar 2 yang berarti bahwa layanan pendaftaran memberikan pengaruh pada kepuasan pelanggan apabila penilaian pada fasilitas lebih dari 23.9872 (0.7496 x 32). Sebaliknya, untuk penilaian fasilitas kurang dari atau sama dengan 23.9872 maka layanan pendaftaran tidak berpengaruh.

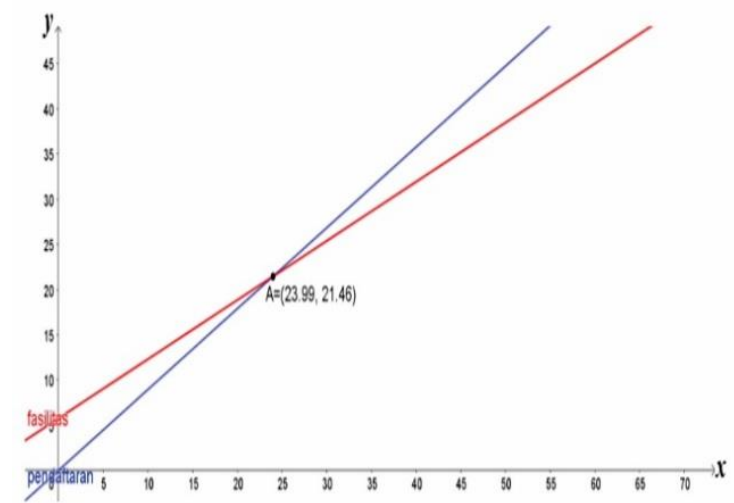

Gambar 2. Grafik perpotongan garis fasilitas dengan layanan pendaftaran

Sedangkan layanan dokter umum memberikan kontribusi tambahan terhadap kepuasan pelanggan

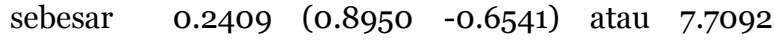
(28.6404 -20.9312). Perpotongan garis pada persamaan 6 dan persamaan layanan dokter umum terjadi pada titik (0.7482, 21.4287) seperti Gambar 3 yang berarti bahwa layanan dokter memberikan pengaruh pada kepuasan pelanggan apabila penilaian pada fasilitas lebih dari 23.9424 (0.7482 x 32). Sebaliknya, untuk penilaian fasilitas kurang dari atau sama dengan 23.9424 maka layanan dokter umum tidak berpengaruh.

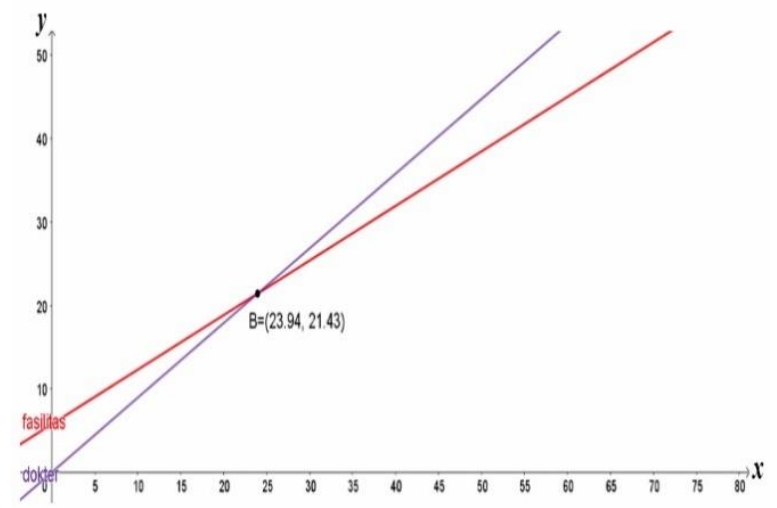

Gambar 3. Grafik perpotongan garis fasilitas dengan layanan dokter umum

Apabila mempertimbangkan layanan obat dan laboratorium memberikan kontribusi tambahan sebesar 0.2393 (0.8934-0.6541) atau 7.656 ( 28.587320.9312). Perpotongan garis pada persamaan 6 dan persamaan layanan obat dan laboratorium terjadi pada titik $(0.7534,21.5377)$ seperti Gambar 4 yang berarti 
bahwa layanan obat dan laboratorium memberikan pengaruh pada kepuasan pelanggan apabila penilaian pada fasilitas lebih dari 24.1088 (0.7534 x 32). Sebaliknya, untuk penilaian fasilitas kurang dari atau sama dengan 24.1088 maka layanan obat dan laboratorium tidak berpengaruh.

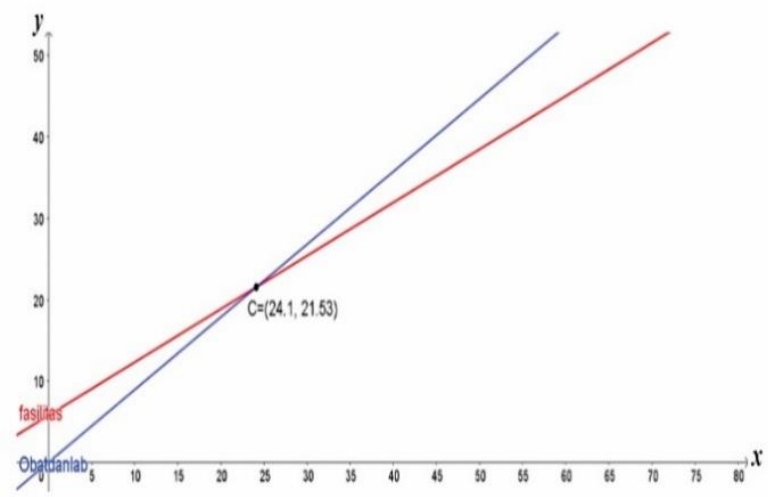

Gambar 4. Grafik perpotongan garis fasilitas dengan layanan obat dan laboratorium

Hasil bobot kategori untuk ketiga fuzzy group yang dilakukan dengan menggunakan FQT ditunjukkan pada Tabel 3 .

Tabel 3. Hasil Bobot Kategori

\begin{tabular}{ccccc}
\hline & \multicolumn{2}{c}{ Bobot Kategori } & \multicolumn{2}{c}{$\begin{array}{c}\text { Penambahan } \\
\text { Kontribusi }\end{array}$} \\
\cline { 2 - 5 } Fuzzy Group & $\begin{array}{c}\text { Sebagai } \\
\text { Koefisien } \\
\mu[x]\end{array}$ & $\begin{array}{c}\text { Sebagai } \\
\text { Koefisien } \\
x\end{array}$ & $\begin{array}{c}\text { Sebagai } \\
\text { Koefisien } \\
\mu[x]\end{array}$ & $\begin{array}{c}\text { Sebagai } \\
\text { Koefisien }\end{array}$ \\
\hline \hline $\begin{array}{c}\text { Layanan } \\
\text { pendaftaran }\end{array}$ & 28.6255 & 0.8945 & 7.6943 & 0.2404 \\
$\begin{array}{c}\text { Layanan } \\
\text { dokter } \\
\text { umum }\end{array}$ & 28.6404 & 0.8950 & 7.7092 & 0.2409 \\
$\begin{array}{c}\text { Layanan } \\
\text { obat dan }\end{array}$ & 28.5873 & 0.8934 & 7.6561 & 0.2393 \\
laboratorium & & & & \\
\hline
\end{tabular}

Pada Tabel 3 terlihat bahwa nilai kontribusi yang terbesar terdapat pada fuzzy group 2 yaitu layanan dokter umum dengan nilai bobot kategorinya sebesar 28.6404 atau 0.8950 dan penambahan kontribusinya sebesar 7.7092 atau 0.2409. Sedangkan fuzzy group yang memberikan kontribusi terendah yaitu layanan obat dan laboratorium.

\section{KESIMPULAN}

Hasil analisis fuzzy group 1 menunjukkan bahwa persamaan regresi layanan pendaftaran adalah $\mathrm{y}=\mathbf{2 8 . 6 2 5 5} \mu[\mathrm{x}]$ yang memberikan kontribusi sebesar 7.6943 pada kepuasan pelanggan. Untuk analisis fuzzy group 2 diperoleh persamaan regresi layanan dokter

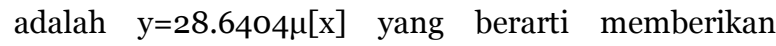
kontribusi sebesar 7.7092 pada kepuasan pelanggan. Sedangkan pada analisis fuzzy group 3 menunjukkan bahwa persamaan regresi layanan obat dan

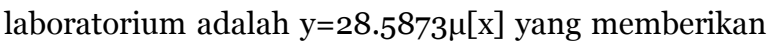
kontribusi sebesar 7.6561 pada kepuasan pelanggan. Sehingga dapat disimpulan bahwa dengan analisis Fuzzy Quantification Theory I, diketahui bahwa layanan dokter memberikan kontribusi terbesar terhadap kepuasan pelanggan, sedangkan yang memberikan kontribusi terkecil adalah layanan obat dan laboratorium.

\section{REFERENSI}

[1] D. Kartikasari, A. Dewanto, F. Rochman," Pengaruh Kualitas Layanan terhadap kepuasan dan kepercayaan di rumah sakit Bunda Kandangan Surabaya,” JAM, vol. 12, 3, pp. 454463, Sept. 2016

[2] H. Mustafidah, Suwarsito," Analisis Minat Belajar Mahasiswa dan Tingkat Kehadiran Dosen pengaruhnya terhadap Tingkat Kelulusan Mahasiswa Menggunakan Fuzzy Quantification Theory," JUITA, vol. II, 2, pp. 85-92, Nov. 2012

[3] H. Mustafidah, Suwarsito," Analysis of Competence Level and the Attendance of the Lecturer in Its Effects on Students Grade Using Fuzzy Quantification Theory,” IJCSI, vol. 11, 4, pp. 75-79, Sept. 2014

[4] R. Adibuana, (2012,Feb). Analisis Regresi [online].

Avaliable:http://rufiismada.files.wordpress.com/ 2012/02/analisis-regresi.pdf . [24 Oktober 2017]

[5] R. Muktiadi, H. Mustafidah,” Fuzzy Quantification System untuk menganalisis pengaruh minat belajar dan tingkat kehadiran mahasiswa terhadap prestasi belajar mahasiswa universitas Muhammadiyah Purwokerto,” JUITA, vol. II, 1, pp. 65-72, May 2012

[6] R. R. Antina," Analisis Kualitas Pelayanan terhadap kepuasan Pasien BPJS di Puskesmas Pandian Kabupaten Sumenep," JPAP, vol. 2, 2, pp. 567-576, Oct. 2016

[7] S. Kusumadewi, H. Purnomo, Aplikasi Logika Fuzzy untuk pendukung keputusan. Graha Ilmu: Yogyakarta,2004; pp 269-310.

[8] S. Mongkaren," Fasilitas dan Kualitas pelayanan pengaruhnya terhadap kepuasan penguna jasa rumah sakit advent manado," Jurnal EMBA, vol. 1, 4, pp. 493-503, Dec. 2013

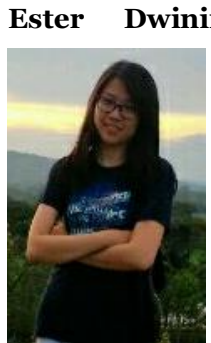

gsih Putri Permatasari Santoso (debora210166@gmail.com ) lahir di Kota Surakarta,9 Agustus 1995. Dia masih menempuh pendidikan tinggi di Program Studi Matematika, Fakultas Sains dan Matematika, Universitas Kristen Satya Wacana (UKSW) Salatiga. Tahun 2018 adalah tahun terakhir ia menempuh studi. Makalah ini merupakan hasil penelitian skripsinya yang dipublikasikan. 
Bambang Susanto (bambangsusanto@staff.uksw.edu) lahir

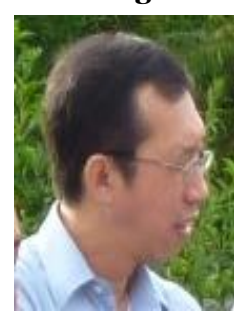

di Ambarawa, Jawa Tengah, pada tanggal 12 Juli 1963. Pada tahun 1992, gelar Magister Sains (M.Si) diperoleh dari Program Pascasarjana Magister Matematika Institut Teknologi Bandung (ITB) dan menyelesaikan program S3 pada tahun 2005 di lembaga yang sama. Sejak tahun 1988 sampai saat ini, ia menjadi Pengajar Tetap di UKSW. Beberapa mata kualiah yang diampu adalah Fungsi Kompleks, Teknik Peramalan dan Analisis Data Multivariat. Salah satu makalah yang ditulisnya besama dengan mahasiswa dan pembimbing utamanya adalah Model Volatilitas Garch(1,1) Dengan Error Student-T Untuk Kurs EUR Dan JPY Terhadap IDR yang dipublikasikan pada Jurnal MIPA, Fakultas MIPA Universitas Negeri Semarang.

Lilik Linawati (lilik.linawati@staff.uksw.edu) lahir di Blitar

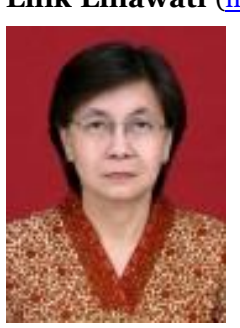

14 agustus 1959. Tahun 1984 lulus S1 Pendidikan Matematika IKIP Sanata Dharma Yogyakarta dan tahun 2003 lulus S2 Ilmu Komputer Universitas Gajah Mada Yogyakarta. Menjadi tenaga akademik tetap di UKSW sejak tahun 1985 pada Pusat Pelayanan Komputer dan pada 1998 bergabung ke Fakultas Sains Matematika Program Studi Matematika. Beberapa matakuliah yang diampu adalah Program Linear, Riset Operasi, Pemodelan Fuzzy, Geometri Euclide, Geometri Analit. Fokus penelitian pada bidang Optimasi dan pembelajaran Matematika. 